\title{
Revisão dos principais genes e proteínas associadas à demência frontotemporal tau-positiva
}

\author{
Review of main genes and proteins associated with tau-positive frontotemporal dementia
}

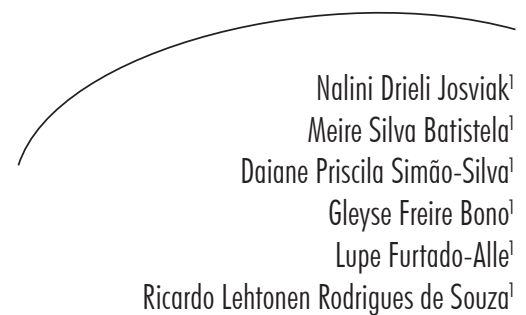

\section{Resumo}

O objetivo desta revisão foi apresentar os genes $A P O E$ e $M A P T$ e as proteínas $A p o E$ e tau como marcadores genéticos que vêm sendo estudados na demência frontotemporal com inclusões tau-positivas, os quais poderão, futuramente, auxiliar no diagnóstico diferencial. A demência frontotemporal é um transtorno neurocognitivo marcado por disfunção dos lobos frontais e temporais, geralmente associada à atrofia dessas estruturas e relativa preservação das regiões cerebrais posteriores. Clinicamente, manifesta-se por volta dos 57 anos de idade, com igual incidência entre homens e mulheres. A demência frontotemporal tem início insidioso e caráter progressivo, com discreto comprometimento da memória episódica, mas com importantes alterações comportamentais, de personalidade e na linguagem. Devido às semelhanças possíveis entre as manifestações clínicas das demências (inclusive a doença de Alzheimer), há grande dificuldade no diagnóstico diferencial, sendo necessário um exame clínico e neuropsicológico detalhado do indivíduo acometido, além de exames bioquímicos e de neuroimagem. O gene $M A P T$ codifica a proteína tau e sua função principal é estabilizar os microtúbulos. Em células nervosas sadias, a proteína tau é normalmente encontrada nos axônios, ao contrário dos achados descritos nos transtornos neurocognitivos, em que a proteína se encontra distribuída no corpo celular e nos dendritos. A apolipoproteína $E$ (ApoE) é uma glicoproteína polimórfica, codificada pelo gene $A P O E$, que tem importante papel na absorção, transporte e redistribuição de colesterol, necessário ao reparo e manutenção do tecido nervoso. Com o aumento da expectativa de vida e controle da natalidade, o envelhecimento populacional tornou-se fato, trazendo consigo maior prevalência de doenças crônico-degenerativas, de modo que é de extrema importância conhecer melhor essas doenças, no sentido de buscar novas formas de tratamento, visto que as demências não dispõem ainda de cura. Sabese que o diagnóstico definitivo da maioria das síndromes demenciais depende do exame neuropatológico, mas conclui-se que, com o avanço tecnológico, bem como técnicas de biologia e genética molecular, novas perspectivas têm surgido para o diagnóstico diferencial e precoce das demências.
Palavras-chave: Demência. Genética. Diagnóstico. Demência Frontotemporal.

Universidade Federal do Paraná. Departamento de Genética, Laboratório de Polimorfismos e Ligação, Setor de Ciências Biológicas. Curitiba, PR, Brasil. 


\section{Abstract}

This review aimed to present the APOE and MAPT gene and ApoE and tau proteins as genetic markers that have been studied in frontotemporal dementia, which may in future help in the differential diagnosis. Frontotemporal dementia is a neurocognitive disorder characterized by frontal and temporal lobes dysfunction, often associated with atrophy of these structures and relative preservation of posterior brain regions. Clinically, it manifests around 57 years-old, with same incidence in men and women. Frontotemporal dementia has an insidious and progressive onset, with a mild impairment of episodic memory, but with significant behavioral, personality and language changes. Due to possible similarities between the clinical manifestations of dementia (including Alzheimer's disease) there is a great difficulty in the differential diagnosis, which needs detailed clinical and neuropsychological examination of individuals affected, further biochemical and neuroimaging exams. $M A P T$ gene encodes tau protein, its main function is to stabilize microtubules. In healthy nerve cells, tau protein is usually found in the axons, in contrast to the findings described in neurocognitive disorders in which protein is distributed in the cell body and dendrites. The apolipoprotein E (ApoE) is a

Key words: Dementia. Genetics. Diagnostic. Frontotemporal Dementia. polymorphic glycoprotein, encoded by the APOE gene, which plays an important role in absorption, transport and redistribution of cholesterol, necessary for the repair and maintenance of nervous tissue. Because of increasing life expectancy and birth control, population aging has become fact, bringing a higher prevalence of chronic diseases, so it is extremely important to know more about these dis eases, in order to seek new ways of treating dementias seen that do not have a cure. It is known that the definitive diagnosis of most dementia depends on neuropathological examination, however, with technological advances and techniques of molecular biology and genetics, new opportunities have emerged for the early and differential diagnosis of dementias.

\section{INTRODUÇÃo}

Demência ou transtorno neurocognitivo maior ${ }^{1}$ se caracteriza pelo declínio progressivo em múltiplos domínios cognitivos, comprometendo as atividades sociais e ocupacionais do indivíduo acometido. $^{2-4}$ As demências podem ser classificadas em duas categorias: degenerativas e não degenerativas. As demências não degenerativas são decorrentes de outras condições patológicas, como os processos infecciosos, traumatismos, deficiências nutricionais, tumores, dentre outros. Já as demências degenerativas têm sua origem predominantemente cortical, como é o caso da demência frontotemporal (DFT) ${ }^{5-7} \mathrm{~A}$ DFT tem início insidioso e caráter progressivo, com discreto comprometimento da memória episódica, mas com importantes alterações comportamentais, de personalidade e alterações na linguagem. ${ }^{8}$

Há três fenótipos clínicos distintos para a DFT. A forma de apresentação mais comum é a DFT comportamental (variante frontal), a qual se caracteriza por progressivas mudanças comportamentais e de personalidade, que incluem comportamento social anormal, padrão de alimentação não usual e comportamentos ritualizados. Ao contrário da doença de Alzheimer, tais sintomas surgem precocemente, a despeito de testes cognitivos normais ou minimamente anormais ao início. 
A segunda variante da DFT manifestase sob a forma de uma afasia de fluência em estágios iniciais, havendo dificuldade para encontrar a palavra certa, porém a compreensão de seu significado encontra-se preservada. O comportamento e a interação social estão frequentemente inalterados até estágios tardios da doença, quando o paciente torna-se mudo, esta variante da DFT também pode ser chamada de afasia progressiva não fluente (APNF).

A terceira forma de apresentação é conhecida como variante temporal da DFT ou demência semântica (DS); caracteristicamente manifesta-se sob a forma de uma afasia progressiva, havendo dificuldade para nomear objetos e compreender palavras (o que reflete a predominância de disfunção no lobo temporal esquerdo), além de reconhecer objetos e faces (refletindo uma disfunção temporal direita).

$\mathrm{Na}$ demência semântica, as alterações comportamentais apresentam-se de forma muito semelhante às alterações da DFT variante frontal; em contrapartida, na APNF as alterações de comportamento quase sempre estão ausentes nos estágios iniciais da doença, podendo aparecer mais tardiamente. ${ }^{5,8,9}$

Além dessas três formas mais comuns, há ainda um subtipo mais raro, a DTF associada à doença do neurônio motor (DFT-DNM). ${ }^{10}$ Apesar dessas sintomatologias bem definidas para DFT, na prática clínica muitos transtornos neurocognitivos apresentam semelhanças ou sobreposição de sintomas, dificultando o diagnóstico clínico diferencial.

Nesse cenário, estudos genéticos tornam-se importantes para a descoberta de marcadores que auxiliem o diagnóstico diferencial entre as demências. Cerca de 30\% a 50\% dos pacientes com DFT comportamental apresentam história familiar positiva, enquanto que para os pacientes com os subtipos DS e APNF, a frequência de historia familiar positiva é bem mais baixa.
Mutações nos genes MAPT e PGRN estão presentes em cerca de $50 \%$ dos casos familiares, porém outras mutações menos frequentes, aproximadamente $5 \%$ dos casos familiares, também já foram descritas para os genes $V C P$, CHMP2B, TARDP e FUS. ${ }^{11-16}$ É importante relembrar que, patologicamente, as DFTs se dividem em tau-positivas e tau-negativas; nesta revisão consideram-se as DFTs tau-positivas, as quais incluem as mutações no gene $M A P T$.

Um dos primeiros genes candidatos em estudos genéticos para a demência frontotemporal (DFT) foi o gene $M A P T$, que codifica a proteína tau (microtubule-associated protein tau). Em 1994, estabeleceu-se pela primeira vez uma relação entre o cromossomo 17 e a DFT. Posteriormente, diversas mutações no gene $M A P T$, associadas à disfunção da proteína tau, foram relacionadas à neurodegeneração e, assim, se ampliou o espectro clínico das alterações neurológicas pelas mutações neste gene. A frequência das mutações no gene $M A P T$ varia entre $0 \%$ e $17 \%$ quando não há caso familiar; porém, quando há história familiar, essa frequência aumenta de $7,6 \%$ a $50 \%$. $^{17,18}$

Um gene muito explorado em estudos com demências é o $A P O E$, especialmente seus alelos e4 e e2. Em 1993, descobriu-se ser o alelo e4 um forte fator der risco genético para a doença de Alzheimer (DA). ${ }^{19}$ Desde então, vários estudos confirmaram que a posse do alelo e4 aumentam o risco para DA. ${ }^{20,21}$ No entanto, o uso de marcadores para esse gene em outras demências ainda permanece ineficaz. ${ }^{22}$

Estudos de associação entre o alelo e4 e DFT são inconclusivos e controversos. Alguns encontraram uma frequência maior deste alelo em pacientes com DFT do que em controles, ${ }^{21,23,24}$ enquanto outros estudos demonstraram frequências equivalentes em ambos. ${ }^{25}$

Outro alelo do gene APOE (e2) também já foi descrito associado em alguns trabalhos liderados pelo grupo de pesquisa de Verpillat, ${ }^{26}$ 
que determinaram as frequências genotípicas do APOE em 94 pacientes, não relacionados, com DFT e 392 controles sem déficits cognitivos ou perturbações comportamentais, encontrando associação significativa para o genótipo e2e2 e DFT. O resultado foi ainda mais significativo no grupo com história familiar positiva. Para a metanálise do polimorfismo do APOE na DFT, o mesmo grupo de pesquisa reuniu dez estudos caso-controle com o genótipo disponível ou informações alélicas (total de 364 pacientes e 2.671 controles), mas o genótipo e2e2 não atingiu significância estatística.

Devido à heterogeneidade de diagnóstico, os pesquisadores analisaram, por um lado, os estudos com amostras neuropatologicamente confirmadas, e por outro, os estudos clínicos de amostras com diagnóstico provável, constatando, assim, aumento significativo na frequência de alelos e2 nos pacientes confirmados neuropatologicamente. Os autores concluíram que o $A P O E$ alelo e2 pode ser fator de risco para a DFT, mas que os dados devem ser interpretados com cautela, devido à raridade do genótipo e2e $2 .{ }^{26}$

Muitos polimorfismos estão envolvidos diretamente com a neurotoxicidade, como por exemplo, mutações no gene da proteína precursora $\beta$-amiloide $(A P P)$, e/ou nos genes dapresenilina (PSEN1 e PSEN2). Mais de 28 mutações nesses genes já foram descritas como associadas à doença de Alzheimer, mas estes podem estar envolvidos no desenvolvimento de outras demências, exatamente pelo fato de alterações funcionais resultarem em toxicidade para o sistema nervoso. ${ }^{27-32}$ No entanto, poucos estudos de associação desses genes com a DFT têm sido realizados.

Mutações no gene da progranulina (PGRN) foram identificados como uma das causas principais da degeneração lobar frontotemporal, embora seus efeitos sobre a disfunção do tecido cerebral e danos ainda devam ser esclarecidos. Um estudo investigou o padrão de neuroimagem em pacientes com DFT, portadores e não portadores de mutação Thr272fs do gene PGRN, e foi encontrada atrofia frontotemporal na substância cinzenta em todos os pacientes com DFT (mais notavelmente naqueles portadores da mutação PGRN Thr272fs), mas não em portadores assintomáticos. ${ }^{32}$

O objetivo desta revisão foi apresentar os genes $A P O E$ e $M A P T$ e suas proteínas $A p o E$ e tau como marcadores genéticos que vêm sendo estudados na demência frontotemporal com inclusões tau-positivas, os quais poderão, futuramente, auxiliar no diagnóstico diferencial.

\section{METODOLOGIA}

Foram realizadas buscas bibliográficas em 2013, sem limitação de data de publicação, nos seguintes bancos de dados: NCBI (PubMed), SciELO, LILACS, Bireme e Medline. Foram utilizadas as seguintes palavras-chave em português: demência frontotemporal, MAPT, ApoE, genes candidatos, proteína tau , apolipoproteína E; e em inglês: frontotemporal dementia, candidate genes, ApoE, MAPT, tau protein.

\section{REVISÃO DO TEMA}

Muitos genes candidatos têm sido alvo de estudos em doenças neurodegenerativas (tabela 1). Assim, para compreender melhor os mecanismos envolvidos nessas doenças, é de essencial importância o conhecimento funcional dos genes e suas proteínas. 
Tabela 1. Estudos de associação de variantes genéticas no desenvolvimento de demências. Brasil, 2013.

\begin{tabular}{ccccc}
\hline Gene & Proteína & Demência & Associação & Referência \\
\hline MAPT & TAU & DFT/DA & Associado & $\begin{array}{c}\text { Cordeiro et al. } .^{17} \\
\text { Liadó et al. }{ }^{18}\end{array}$ \\
ApoE (e4) & Apolipoproteína E & DFT/DA & Associado & Schneider et al. ${ }^{24}$ \\
ApoE (e4) & Apolipoproteína E & DFT & Não associado & Pickering-Brown \\
et al. ${ }^{25}$
\end{tabular}

$\mathrm{DA}=$ doença de Alzheimer; DFT= demência frontotemporal.

\section{Gene MAPT e proteína tau}

A proteína tau faz parte da família das proteínas associadas aos microtúbulos (microtubule-associated proteins - MAPT). A principal função das MAPTs é estabilizar os microtúbulos pela agregação da tubulina. O gene $M A P T$, que codifica a proteína tau associada ao microtúbulo (MAPT - 17q21.1), possui 16 éxons e sua transcrição é complexa, dando origem a 12 cópias de RNAm por splicing alternativo e seis isoformas da proteína. Embora a proteína tau seja expressa em todo o sistema nervoso central do ser humano adulto, os transcritos do MAPT são diferencialmente expressos no sistema nervoso, dependendo do estágio de maturação neuronal e do tipo do neurônio. ${ }^{33-36}$
No cérebro humano, a tau é uma proteína solúvel que se apresenta em seis isoformas derivadas do splicing alternativo de $\mathrm{RNAm}^{37} \mathrm{e}$ compostas por 352-441 resíduos de aminoácidos. O splicing alternativo dos éxons 2, 3 e 10 resulta na presença de seis diferentes isoformas que contêm, respectivamente, nenhuma, uma ou duas inserções no segmento aminoterminal. $\mathrm{O}$ splicing alternativo do éxon 10 produz isoformas 4R ou 3R da tau, dependendo, respectivamente, da presença ou da ausência da sequência de aminoácidos codificada por ele. Em mamíferos, apenas as isoformas pequenas da tau são encontradas no cérebro fetal; essas isoformas não apresentam nenhuma inserção $3 \mathrm{R}$ na sua estrutura primária. Já no cérebro adulto, todas as isoformas da tau são expressas. ${ }^{38}$ 
A relação entre as isoformas $3 R$ e $4 R$ da tau é geralmente de 1:1, visto que alterações nessa razão estão relacionadas a certos mecanismos de neurodegeneração. ${ }^{39}$ Ambas isoformas ocorrem nas DFTs, mas o predomínio da isoforma 4R é característico na degeneração corticobasal (DCB), na paralisia supranuclear progressiva (PSP) e na doença argirofílica granular. ${ }^{40}$

Em células nervosas sadias, a proteína tau é normalmente encontrada nos axônios, ao contrário dos achados descritos nos transtornos neurodegenerativos, em que a proteína se encontra distribuída no corpo celular e nos dendritos. A proteína tau pode ser encontrada na forma solúvel ou insolúvel; esta última é identificada nos filamentos helicoidais pareados (FHP), que são o principal componente dos emaranhados neurofibrilares. Estes são resultado da proteína tau alterada, sendo constituídos por isoformas diferentes em doenças neurodegenerativas diferentes, sugerindo que o splincing é de fundamental importância para o processo neuropatológico. ${ }^{35}$

Os filamentos helicoidais pareados (FHP) apresentam de seis a oito grupos fosfato por molécula de proteína tau, o que, em comparação com o grau de fosforilação usual da proteína tau em cérebros sadios (em torno de dois grupos fosfato por molécula), permite afirmar que a proteína tau identificada nos FHP encontra-se em estado hiperfosforilado.

A proteína tau controla a dinâmica dos microtúbulos durante a maturação e o crescimento dos neuritos. Sendo a maior proteína do citoesqueleto, a hiperfosforilação da tau afeta funções biológicas e morfológicas nos neurônios. A fosforilação da tau in vitro se dá pela ação de mais de dez quinases dirigidas aos seus sítios de serina e/ou tirosina. Essas quinases são divididas em dois grandes grupos de proteína: proteína quinase dirigida por prolina e proteína quinase não dirigida por prolina. Nos tecidos cerebrais, o estado de fosforilação da tau resulta da ação conjunta de várias quinases e fosfatases, muitas das quais operam coordenadamente para regular sua fosforilação. ${ }^{38,39}$

A proteína tau também promove a interação entre a actina e os neurofilamentos, o que sugere inter-relação dos microtúbulos com outros componentes do citoesqueleto. A proteína tau interage com outras organelas citoplasmáticas, permitindo a ligação entre microtúbulos e mitocôndrias. Os domínios de projeção N-terminal da proteína tau permitem uma interação com a membrana plasmática neuronal. ${ }^{40,41}$ A hiperfosforilação anormal da proteína tau pode ser o resultado do aumento da atividade das tauquinases, da subsensibilização das suas fosfatases ou de ambos os mecanismos. O estado de fosforilação da proteína tau é modificado dinamicamente ao longo do desenvolvimento. A tau fetal mantémse usualmente hiperfosforilada, sendo essa característica atenuada à medida que ocorre a maturação do sistema nervoso central, com a progressiva ativação das fosfatases. ${ }^{38}$

Em humanos com transtornos degenerativos, a proteína tau está presente na forma de filamentos anormais insolúveis e hiperfosforilados. ${ }^{37}$ Doenças neurodegenerativas com inclusões de neurofilamentos e/ou agregados de proteína tau são classificadas em quatro grupos: tauopatias, alfasinucleinopatias, doença poliglutamínica e doenças com ubiquitina. O grupo das taupatias é o mais prevalente, incluindo a DA e a DFT. Todas essas doenças têm em comum a presença de grandes quantidades de agregados de proteína tau. ${ }^{42-44}$ Nas DFTs, agregados de proteína tau estão presentes em, aproximadamente, 40\% dos casos. $^{45}$ Portanto, o acúmulo intracelular da proteína tau hiperfosforilada em neurônios ou células gliais é um importante marcador biológico das tauopatias. 
Vários estudos demonstraram que a hiperfosforilação reduz a capacidade de a tau estabilizar os microtúbulos. Isso compromete a dinâmica microtubular, afetando o transporte intraneuronal, resultando em efeitos deletérios sobre diversos processos celulares. Todos os defeitos na proteína tau alteram o transporte axonal, fatores vitais e necessários para a manutenção da homeostase neuronal. A regulação da dinâmica dos microtúbulos (estabilização e desestabilização) é essencial para a preservação da morfologia e da função da célula nervosa, da qual depende a manutenção da viabilidade celular. ${ }^{46-48}$ A hiperfosforilação da tau favorece a formação de agregados, bloqueando o tráfego intracelular de proteínas neurotróficas e outras proteínas funcionais, resultando em perda ou declínio no transporte axonal ou dendrítico nos neurônios.

O aumento da expressão da tau também causa mudanças na morfologia celular, retarda o crescimento e provoca alterações importantes na distribuição de organelas transportadas por proteínas motoras dependentes demicrotúbulos. A hiperfosforilação da tau presente no citosol durante estágios iniciais de degeneração neurofibrilar induz mudanças conformacionais que precedem sua agregação. Existem algumas controvérsias sobre a polimerização da tau e sua toxicidade, e estudos recentes mostram que essa agregação da tau é tóxica para as células, estando sua polimerização associada à perda da atividade biológica essencial para promover a estabilidade e coesão dos microtúbulos. No entanto, a defosforilação da tau hiperfosforilada e dos filamentos helicoidais pareados faz com que a proteína recupere suas atividades biológicas normais. $^{38,49}$

Os casos de DFT com parkinsonismo ligado ao cromossomo 17 (FTDP-17) são caracterizados pela presença e inclusão de filamentos compostos por proteína tau hiperfosforilada. ${ }^{50}$ Até o momento, mais de 30 mutações diferentes do gene que codifica a proteína tau foram descritas em pacientes com DFTP-17. ${ }^{38}$ Contudo, é importante lembrar que a frequência de mutações do gene codificador da proteína tau nos casos de DFT esporádica é baixa, apresentando frequências muito maiores em casos com história familiar positiva (cerca de 60\%). ${ }^{51-54}$

\section{Gene APOE e apolipoproteína E (ApoE)}

O gene $A P O E$ contém quatro éxons, três íntrons e comprimento aproximado de $3,7 \mathrm{~Kb}{ }^{55,56}$ Possui três alelos comuns (e2, e3 e e4) e produz três isoformas protéicas que diferem somente em dois resíduos de aminoácidos nas posições 112 e $158,{ }^{57}$ sendo $A P O E 2$ caracterizado por Cys112 e Cys158; APOE3 por Cys112 e Arg158 e APOE4 por Arg112 e Arg158. ${ }^{58}$ Outras variantes extremamente raras do $A P O E$ são a $A P O E 1$, APOE5 e APOE7.

Em populações caucasoides, a frequência de $A P O E 2$ é de $8 \%$; $A P O E 3$, de $78 \%$; e APOE4, $14 \% .^{59} \mathrm{O}$ alelo APOE2 tem sido associado à proteção contra o desenvolvimento da $\mathrm{DA},{ }^{19}$ enquanto o alelo APOE4 em homozigose representa um risco dez vezes maior que os outros genótipos na manifestação da DA. ${ }^{28,60}$ Os doentes expressando o alelo APOE4 têm uma idade mais precoce de início e capacidade reduzida para a plasticidade sináptica. ${ }^{61}$ Cerca de 40-65\% dos pacientes com DA têm pelo menos uma cópia do $A P O E 4 .^{62}$

A transcrição do gene $A P O E$ resulta em um RNAm de 1163 pb. ${ }^{63} \mathrm{E}$ a tradução do RNAm produz uma forma isoproteica pré- $A p o E$ de 317 aminoácidos. A forma isoproteica pré-ApoE é translocada através da membrana do retículo endoplasmático com processamento proteolítico e glicosilação, para gerar a proteína madura de 34,2 kDa, composta de 299 aminoácidos (apolipoproteína E). ${ }^{64}$ 
A apolipoproteína E (ApoE) é uma glicoproteína polimórfica com dois importantes domínios funcionais, o domínio N-terminal, que contém as principais regiões de ligação ao receptor, e o domínio C-terminal com a região de ligação lipídica, já associada à ligação da A.$^{65,66}$ A ApoE tem importante papel na absorção, transporte e redistribuição de colesterol, que é necessário ao reparo e manutenção do tecido nervoso. ${ }^{67}$ É sintetizada em vários órgãos, principalmente no fígado, pelas células hepáticas parenquimatosas e no encéfalo pelos astrócitos, consistindo de uma das principais lipoproteínas do sistema nervoso central ${ }^{68,69} \mathrm{~A} A p o \mathrm{E}$ atua como principal veículo no transporte de lipídios e colesterol no fluido cerebroespinal e intervém nos processos de regeneração do tecido nervoso, na regulação imunológica e na modulação do crescimento e diferenciação celular. ${ }^{67}$

\section{REFERÊNCIAS}

1. American Psychiatric Association. Diagnostic and Statistical Manual of Mental Disorders. 5th ed. Arlington: American Psychiatric Association; 2013.

2. Frota NAF, Nitrini R, Damasceno BP, Forlenza O, Dias-Tosta E, Da Silva AB, et al.Critérios para o diagnóstico de doença de Alzheimer. Dement Neuropsychol 2011;5(Suppl 1): 5-10.

3. Neto JG, Tamelini MG, Forlenza OV. The Differential Diagnosis of Dementia. Rev Psiquiatr Clín 2005;32(3):119-30.

4. Knopman DS, Dekosky ST, Cummings JL, Chui H, Corey-Bloom J, Relkin N, et al. Practice parameter: diagnosis of dementia (an evidenced based review). Report of the Quality Standards Subcommittee of the American Academy of Neurology. Neurology 2001;56(9):1143-53.

5. Fornari LHT, Garcia LP, Hilbig A, Fernandez. The several faces of dementia syndrome: how to diagnose clinically? Sci Med 2010;20(2):185-83.

6. Gorzoni ML, Pires SL. Aspectos clínicos da demência senil em instituições asilares. Rev Psiquiatr Clín 2006;33(1):18-23.
Pesquisas detectaram também aumento da expressão de $A p o E$ no córtex frontal e temporal e no hipocampo de pacientes com DA neuropatologicamente confirmada. ${ }^{70-72}$ Assim, é possível que a expressão da $A p o E$ também esteja alterada em pacientes diagnosticados com DFT.

\section{CONSIDERAÇÕES FINAIS}

Os quadros demenciais em geral são resultados de uma rede biológica complexa; assim, o melhor entendimento da base genética em conjunto com os fatores ambientais, tais como escolaridade, nutrição e estilo de vida é o caminho para um diagnóstico mais confiável e diferenciado ente as demências. No caso da demência frontotemporal, esses conhecimentos resultarão não só em um diagnóstico mais preciso, como também no desenvolvimento de drogas eficazes, já que a mesma ainda não possui uma cura.

7. Allegri RF, Harris P, Serrano C, Delavald N. Perfis diferenciais de perda de memória entre a demência frontotemporal e a do tipo Alzheimer. Psicol Reflex Crit 2001;142(2):317-24.

8. Araújo CLO, Nicoli JS. A bibliographic review of the mainly dementias which take on brazilian population. Rev Kairós 2010;13(1):231-44.

9. Gallucci NJ, Tamelini MG, Forlenza OV. Diagnóstico diferencial das demências. Rev Psiquiatr Clín 2005;32(3):119-30

10. Seelaar H. Frontotemporal dementia: clinical, genetic, and pathological heterogeneity [tese]. Rotterdam: Erasmus Universiteit Rotterdam; 2011.

11. Seelaar H, Kamphorst W, Rosso SM, Armani A, Masdjedi R, De Koning I, et al. Distinct genetic forms of frontotemporal dementia. Neurology 2008;71(16):1220-6.

12. Chow TW, Miller BL, Hayashi VN, Geschwind DH. Inheritance of frontotemporal dementia. Arch Neurol 1999;56(7):817-22. 
13. Goldman JS, Farmer JM, Wood EM, Johnson JK, Boxer A, Neuhaus J, et al. Comparison of family histories in FTLD subtypes and related tauopathies. Neurology 2005;65(11):1817-9.

14. Rosso SM, Donker Kaat L, Baks T, Joosse M, De Koning I, Pijnenburg y, et al. Frontotemporal dementia in The Netherlands: patient characteristics and prevalence estimates from a population-based study. Brain 2003;126(Pt 9):2016-22.

15. Stevens M, Van Duijn CM, Kamphorst W, De Knijff P, Heutink P, Van Gool WA,et al. Familial aggregation in frontotemporal dementia. Neurology 1998;50(6):1541-45.

16. Rohrer JD, Guerreiro R, Vandrovcova J, Uphill J, Reiman D, Beck J, et al. The heritability and genetics of frontotemporal lobar degeneration. Neurology 2009;73(18):1451-56.

17. Cordeiro Q, Zung S, Vallada H. Genetics of dementia. Arq Med Hosp Fac Cienc Med Santa Casa São Paulo 2008;53(1):24-30.

18. Liadó A, Gaig C, Molinuevo JL. Genética de las enfermidades neurodegenerativas más prevalentes. Med Clin (Barc) 2006;126(17): 662-70.

19. Corder EH, Saunders AM, Strittmatter WJ, Schmechel DE, Gaskell PC, Small GW, et al. Gene dose of apolipoprotein $\mathrm{E}$ type 4 allele and the risk of Alzheimer's disease in late onset families. Science 1993;261(5123):921-3.

20. Roses AD. Apolipoprotein $\mathrm{E}$ alleles as risk factors in Alzheimer's disease. Ann Rev Med 1996;(47):387-400.

21. Farrer LA, Abraham CR, Volicer L, Foley EJ, KowallNW, McKee AC, et al. Allele epsilon 4 of apolipoprotein $\mathrm{E}$ shows a dose effect on age at onset of pick disease. Exp Neurol 1995;136(2):162-70.

22. Minthon L, Hesse C, Sjögren M, Englund E, Gustafson L, Blennow K. The apolipoprotein E e4 allele frequency is normal in fronto temporal dementia but correlates with age at onset of disease. Neurosci Lett 1997;226(1):65-7.

23. Frisoni GB, Calabresi L, Geroldi C, Bianchetti A, D’Acquarica AL, Govoni S, et al. Apolipoprotein $\mathrm{E} \varepsilon 4$ allele in Alzheimer's Disease and Vascular Dementia. Dement Geriatr Cogn Disord 1994;5(5):240-2.

24. Schneider JA, Gearing M, Robbins RS, De I'Aune W, Mirra SS. Apolipoprotein E genotype in diverse neurodegenerative disorders. Ann Neurol 1995;38(1):131-5
25. Pickering-Brown SM, Roberts D, Owen F, Neary D. Apolipoprotein E4 alleles and non-Alzheimer's disease forms of dementia. Neurodegeneration 1994;4:95-6.

26. Verpillat P, Camuzat A, Hannequin D, ThomasAnterion C, Puel M, Belliard S, et al. Apolipoprotein $\mathrm{E}$ gene in frontotemporal dementia: an association study and meta-analysis. Eur J Hum Genet 2002;10(7):399-405.

27. Schellenberg GD, Bird TD, Wijsman EM, Orr HT, Anderson L, Nemens E, et al. Genetic linkage evidence for a familial Alzheimer's disease locus on chromosome 14. Science. 1992;258(5082):668-71.

28. Tanzi RE, Vaula G, Romano DM, Mortilla M, Huang TL, Tupler RG, et al. Assessment of amyloid betaprotein precursor gene mutations in a large set of familial and sporadic Alzheimer disease cases. Am J Hum Genet 1992;51(2):273-82.

29. Rogaev EI, Sherrington R, Rogaeva EA, Levesque G, Ikeda M, Liang Y, et al. Familial Alzheimer's disease in kindreds with missense mutations in a gene on chromosome 1 related to the Alzheimer's disease type 3 gene. Nature 1995;376(6543):775-8.

30. Sherrington R, Froelich S, Sorbi S, Campion D. Chi $\mathrm{H}$, Rogaeva A, et al. Alzheimer's disease associated with mutations in presenilin 2 is rare and variably penetrant. Hum Mol Genet 1996;5(7):985-8.

31. Tabaton M, Tamagno E. The molecular link between beta- and gamma-secretase activity on the amyloid beta precursor protein. Cell Mol Life Sci 2007;64(17):2211-8.

32. Borroni B, Alberici A, Cercignani M, Premi E, Serra L, Cerini C, et al. Granulin mutation drives brain damage and reorganization from preclinical to symptomatic FTLD. Neurobiol Aging 2012;33(10):2506-20.

33. NCBI. National Center for Biotechnology Information [Internet]. Bethesda: NCBI: [1988?] acesso em 05 jun 2013. Disponível em http://www. ncbi.nlm.nih.gov/.

34. Trabzuni D, Wray S, Vandrovcova J, Ramasamy A, Walker $\mathrm{R}$, Smith $\mathrm{C}$, et al. MAPT expression and splicing is differentially regulated by brain region: relation to genotype and implication for tauopathies. Hum Mol Genet 2012;21(18):4094-4103.

35. Kikkawa M, Ishikawa T, Nakata T, Wakabayashi T, Hirokawa N. Direct visualization of the microtubule lattice seam both in vitro and in vivo. J Cell Biol 1994:127(6 Pt 2):1965-71. 
36. Goedert M. Tau protein and neurodegeneration. Semin Cell Dev Biol 2004;15(1):45-9.

37. Paula VJR, Guimarães FM, Forlenza OV. The role of TAU protein in the pathophysiology of frontotemporal dementia. Rev Psiquiatr Clín 6(5): 197-202.

38. Wang JZ, Liu F. Microtubule-associated tau protein in development, degeneration and protection of neurons. Prog Neurobiol 2008;85(2):148-75.

39. Knibb JA, Kipps CM, Hodges JR. Frontotemporal dementia review. Curr Opin Neurol 2006;19:565-71.

40. Brandt R, Hundelt M, Shahani N. Tau alteration and neuronal degeneration in tauopathies: mechanisms and models. Biochim Biophys Acta;1739(2-3):331-54.

41. Buée L, BussièrreT, Buée-Scherrer V, Delacourte A, Hof Patric R. Tau protein isoforms, phophorylation and role in neurodegenerative disorders. Brain Res Rev 2000;33(1):95-130.

42. Robert M, Mathuranath PS. Tau and tauopathies. Neurol India 2007;55(1):11-6.

43. Hasegawa M. Biochemistry and molecular biology of Tauopathies. Neuropathol 2006;26(5):484-90.

44. Förstl H, Gratz S, Hahn U, Schwarz J, Jarniq M. Dementia with Lewy bodies and reduced dopamine transporter binding indicates significant acetylcholine deficiency. Dtsch Med Wochenschr 2008;133 Suppl 1:11-4.

45. Kertesz A, McMonagle P, Blair M, Davidson W, Munoz DG. The evolution and pathology of frontotemporal dementia. Brain. 2005;128(9): 19962005.

46. Stoothoff WH, Johnson GV. Tau phosphorylation: physiological and pathological consequences. Biochim Biophys Acta 2005;1739(2-3):280-97.

47. Corbo CP, Alonso AC. Therapeutic targets in Alzheimer's disease and related tauopathies. Prog Mol Biol Transl Sci 2011;98:47-83.

48. Jayapalan S, Natarajan J. The role of CDK5 and GSK3B kinases in hyperphosphorylation of microtubule associated protein tau (MAPT) in Alzheimer's disease. Bioinformation 2013;9(20):1023-30.

49. Ballatore C, Lee VM, Trojanowski JQ. Tau-mediated neurodegeneration in Alzheimer's disease and related disorders. Nat Rev Neurosci 2007; 8(9):663-72.

50. Weder ND, Aziz Rehan, Wilkins K, Tampi RR. Frontotemporal dementias: a review. Ann Gen Psychiatry 2007;6(15):1-10.

51. Sjögren M, Andersen C. Frontotemporal dementia: a brief review. Mech Ageing Dev 2006;127(2):180-7.
52. Taniguchi S, McDonaqh AM, Pickering-Brown SM, Umeda Y, Iwatsubo T, Hasegawa M, et al. The neuropathology of frontotemporal lobar degeneration with respect to the cytological and biochemical characteristics of tau protein. Neuropathol Appl Neurobiol 2004;30(1):1-18.

53. Sutherland GT, Nowak G, Halliday GM, Kril JJ. Tau isoform expression in frontotemporal dementia without tau deposition. J Clin Neurosci 2007;14(12):1182-5.

54. Chang PW, Tsui SK, Liew C, Lee CC, Wayne MM, Fung KP. Isolation, characterization, and chromosomal mapping of a novel cDNA clone encoding human selenium binding protein. J Cell Biochem 1997;64(2):217-24.

55. Paik YK, Chang DJ, Reardon CA, Davies GE, Mahley RW, Taylor JM. Nucleotide sequence and structure of the human apolipoprotein E gene. Proc Natl Acad Sci U.S.A. 1985;82(10):3445-9.

56. Weisgraber KH, Rall SC Jr, Mahley RW. Human E apoprotein heterogeneity: cysteine-arginine interchanges in the aminoacid sequence of the apo-E isoforms. J Biol Chem 1981;256(17):9077-83.

57. Mahley RW, Rall SC Jr. The Metabolic and molecular basis of inherited disease. 7th. New York: McGrawHill; 1995.

58. Martins RN, Clarnette R, Fisher C, Broe GA, Brooks WS, Montgomery P, et al. ApoE genotypes in Australia: roles in early and late onset Alzheimer's disease and Down's syndrome. Neuroreport 1995;6(11):1513-6.

59. Laws SM, Hone E, Gandy S, Martins RN. Expanding the association between the $A p o E$ gene and the risk of Alzheimer's disease: possible roles for $A p o E$ promoter polymorphisms and alterations in $A p o E$ transcription. J Neurochem 2003;84(6):1215-36.

60. Lai MK, Tsang SWY, Garcia-Alloza M, Minger SL, Nicoll JAR, Esiri MM, et al. Selective effects of the APOE epsilon4 allele on presynaptic cholinergic markers in the neocortex of Alzheimer's disease. Neurobiol Dis 2006;22(3):555-61.

61. Huang Y. Apolipoprotein E and Alzheimer disease. Neurology 2006;66(1):79-85.

62. McLean JW, Elshourbagy NA, Chang DJ, Mahley RW, Taylor JM. Human apolipoprotein E RNAm. cDNA cloning and nucleotide sequencing of a new variant. J Biol Chem 1984;259(10):6498-504.

63. Rall SC Jr, Weisgraber KH, Mahley RW. Human apolipoprotein E. The complete amino acid sequence. J Biol Chem 198;257(8):4171-8 
64. Phu MJ, Hawbecker SK, Narayanaswami V.

Fluorescence resonance energy transfer analysis of apolipoprotein E C-terminal domain and amyloid beta peptide (1-42) interaction. J Neurosci Res 2005;80(6):877-86.

65. Tamamizu-Kato S, Cohen JK, Drake CB, Kosaraju MG, Drury J, Narayanaswami V. Interaction with amyloid beta peptide compromises the lipid binding function of apolipoprotein E. Biochemistry 2008;47(18):5225-34.

66. Mahley RW, Rall SC Jr. Apolipoprotein E: far more than a lipid transport protein. Annu Rev Genomics Hum Genet 2000;1:507-37.

67. Mahley RW. Apolipoprotein E: cholesterol transport protein with expanding role in cell biology. Science 1988;240(4852):622-30.

68. Mahley RW, Innerarity TL, Rall SC Jr, Weisgraber KH. Plasma lipoproteins: apolipoprotein structure and function. J Lipid Res 1984;25(12):1277-94.
69. Boyles JK, Pitas RE, Wilson E, Mahley RW.

Apolipoprotein $\mathrm{E}$ associated with astrocytic glia of the central nervous system and with nonmyelinating glia of the peripheral nervous system. J Clin Invest 1985;76(4):1501-13.

70. Yamada T, Kondo A, Takamatsu J, Tateishi J, Goto I. Apolipoprotein E mRNA in the brains of patients with Alzheimer's disease. J Neurol Sci 1995;(129):56-61.

71. Yamagata K, Urakami K, Ikeda K, Ji Y, Adachi Y, Arai $\mathrm{H}$, et al. High expression of apolipoprotein E mRNA in the brains with sporadic Alzheimer's disease. Dement Geriatr Cogn Disord 2001;12(2)):57-62.

72. Zarow C, Victoroff J. Increased apolipoprotein E mRNA in the hippocampus in Alzheimer disease and in rats after entorhinal cortex lesioning. Exp Neurol 1998;149(1):79-86. 